\title{
Clinical drug-drug interactions of bosentan, a potent endothelial receptor antagonist, with various drugs: Physiological role of enzymes and transporters
}

\author{
Nuggehally R. Srinivas \\ Suramus Bio, J. P. Nagar, I Phase Bangalore 560078, Karnataka, India
}

\begin{abstract}
Bosentan, an endothelin-1 (ET) receptor antagonist is an important drug for the effective management of patients with pulmonary arterial hypertension. Bosentan has a rather complicated pharmacokinetics in humans involving multiple physiological components that have a profound influence on its drug disposition. Bosentan is mainly metabolized by cytochrome P450 (CYP) 3A4 and 2C9 enzymes with the involvement of multiple transporters that control its hepatic uptake and biliary excretion. The involvement of phase 2 metabolism of bosentan is a key to have an enhanced biliary excretion of the drug-related products. While bosentan exhibits high protein binding restricting the drug from extensive distribution and significant urinary excretion, bosentan induces its own metabolism by an increased expression of CYP3A4 on repeated dosing. Due to the above properties, bosentan has the potential to display drug-drug interaction with the co-administered drugs, either being a perpetrator or a victim. The intent of this review is manifold: a) to summarize the physiological role of CYP enzymes and hepatic-biliary transporters; b) to discuss the mechanism(s) involved in the purported liver injury caused by bosentan; c) to tabulate the numerous clinical drug-drug interaction studies involving the physiological interplay with CYP and/or transporters; $d$ ) to provide some perspectives on dosing strategy of bosentan.
\end{abstract}

Key words: Bosentan - Drug-drug interaction - Pharmacokinetics - CYP3A4 - Transporters - Biliary excretion - Hepatic uptake - Endothelin receptor antagonist

\begin{abstract}
Abbreviations: AUC, area under the plasma concentration versus time curve; BCRP, breast cancer resistance protein; BSEP, bile sat export pump; CL, systemic clearance; CYP, cytochrome P450; DDI, drug-drug interaction; ERAs, endothelin receptor antagonists; ET, endothelin-1; MRP2, multidrug resistance-associated protein 2; NTCP, Na+ taurocholate co-transporting polypeptide; OATP, organic anion transporter protein; $\mathrm{PAH}$, pulmonary arterial hypertension; $\mathrm{PDE}-5$, phosphodiesterase type 5; Pgp, P-glycoprotein; UGT, UDP glucuronosyl transferase; ULN, upper limit of normal.
\end{abstract}

\section{Introduction}

Pulmonary arterial hypertension (PAH) is a debilitating and fatal disease involving the pulmonary vasculature that progresses over time; essentially the luminal space in the pulmonary vasculature is drastically reduced due to continuous proliferation of both epithelial and smooth muscle cells along

Correspondence to: Nuggehally R. Srinivas, Suramus Bio, J. P. Nagar, I Phase Bangalore 560078, Karnataka, India

E-mail: srini.suramus@yahoo.com with extracellular matrix (McLaughlin et al. 2009; Tuder et al. 2009). The narrowing of the luminal space translates into an increased pulmonary arterial pressure leading to varying degrees of clinical events such as shortness of breath, reduced functional capacity, causing right heart failure and death (Badesch et al. 2009). In spite of the availability of three distinct drug classes with unique mechanisms of action such as prostacyclin and prostacyclin analogues (comprising of epoprostenol, treprostinil, iloprost), endothelin receptor antagonists (ERAs; comprising of bosentan, ambrisentan, sitaxsentan and macitentan), and phosphodiesterase type 5 
(PDE-5) inhibitors (comprising of sildenafil, tadalafil) the prognosis of the PAH patients remains poor (Barst et al. 2009; Wu et al. 2013; Patel et al. 2015).

Bosentan was the first approved ERA to treat PAH. Bosentan is a specific and competitive antagonist at the endothelin-1 (ET) receptors acting on both receptor subtypes $\mathrm{ET}_{\mathrm{A}}$ and $\mathrm{ET}_{\mathrm{B}}$; although bosentan carries more affinity towards $\mathrm{ET}_{\mathrm{A}}$ receptor subtype. Since ET plays a significant and central role in the pathogenesis and progression of $\mathrm{PAH}$ (Verhaar et al. 1998; Galie et al. 2004) the effective blockade of ET receptors by the pharmacologic intervention (i.e., bosentan) is expected to aid in reversing vasoconstriction and proliferative properties of the ET peptides which are overwhelmingly produced in the PAH patients.

Bosentan is a compound with interesting pharmacokinetic properties that includes high protein binding, cytochrome P450 (CYP)-related metabolism, altered pharmacokinetics due to auto-induction, phase 2-related metabolisms, and involvement of drug transporters in its biliary excretory pathways (Weber et al. 1999a, 1999b; Dingemanse et al. 2004). Owing to the above properties, bosentan is a candidate that has the propensity to manifest drug-drug interaction potential with the co-administered drugs, either being a perpetrator or a victim, as the case may be.

\section{Scope}

The focus of the review is manifold: a) to provide an overview of the physiological role including the CYP enzymes and hepatic-biliary transporters that govern the drug disposition of bosentan; b) to provide the mechanistic basis for the purported liver injury caused by bosentan and other drugs that belong to the ERA class; c) to review the various drug-drug interaction clinical studies of bosentan either as a perpetrator or victim due to the interplay with CYP and/or transporters (Table 1); d) to provide some perspectives on the dosing strategy in lieu of the complicated disposition of bosentan.

\section{Salient features of human disposition of bosentan}

Regardless of intravenous or oral dosing, almost complete recovery (i.e., 92 to $95 \%$ ) of the radioactivity of the administered dose occurred in 3 to 5 days in human subjects (Weber et al. 1999b). Almost negligible radioactivity was observed in the urine suggesting that renal pathway was insignificant for the overall disposition of bosentan. Since majority of the radioactivity was found in the feces, biliary excretion played a critical role in the disposition of bosentan. It was noted that the majority of the circulatory radioactivity, without regard to oral or intravenous route, was represented by the intact parent drug (75 to 80\%) and the remainder of radioactivity was represented by the two major metabolites of bosentan, namely: Ro 48-5033 and Ro 47-8634 (Weber et al. 1999b).

Therefore, the data clearly established that hepatic metabolism was an important component for the elimination of bosentan followed by an effective biliary excretion of both intact bosentan and the metabolites (Weber et al. 1999b). Since the half-life for bosentan was short ( $4-5 \mathrm{~h})$, it necessitated every twelve hour (q12h) oral dosing of bosentan (Webber et al. 1999a). CYP3A4 and CYP2C9 are responsible for the metabolism of bosentan and inhibition of these two enzymatic pathways may cause enhanced oral bioavailability of bosentan. Also, any degree of hepatic dysfunction can potentially alter the pharmacokinetics of bosentan because of dependence on the hepatic metabolism. Upon multiple dosing, bosentan caused time-dependent auto-induction of CYP3A4 enzymes reducing its own exposure (Webber et al. 1999a) and as a consequence of auto-induction the pharmacokinetics of the co-administered drugs that are metabolized by CYP3A4 enzyme may potentially get affected.

\section{Understanding molecular mechanisms}

\section{Role and functionalities of enzymes and transporters}

Fahrmayr et al. (2013) investigated the liver uptake of bosentan, formation of Phase 1 metabolite(s), conjugative Phase 2 metabolic reactions, and efflux of the Phase 2 metabolite of bosentan using transfected cell lines that carried multiple functionalities. In order to achieve, they developed a MDCKIIOATP1B1-CYP3A4-UGT1A1-MRP2 quadrupletransfected cell line (Figure 1).

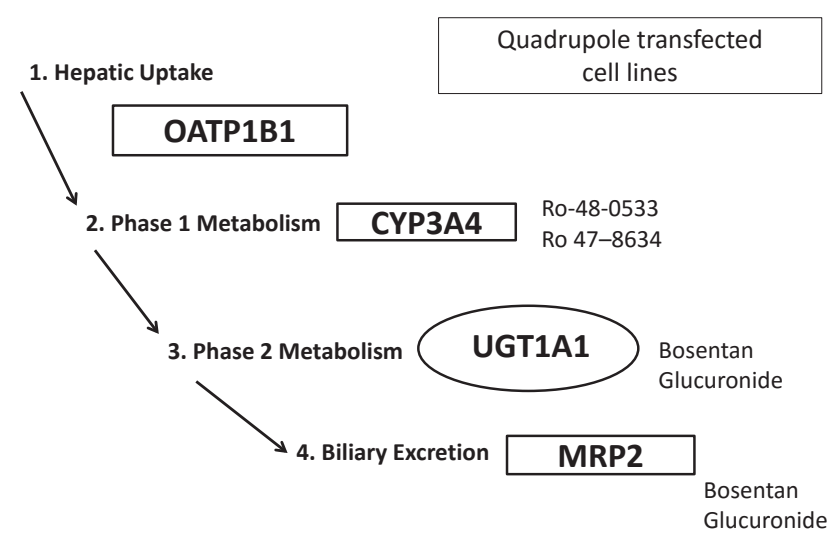

Figure 1. Schematic representation of the quadrupole transfected cell lines that carries various enzymatic and transporter functions: 1) hepatic uptake transporter (OATP1B1); 2) Phase 1 metabolism (CYP3A4); 3) Phase 2 metabolism (UGT1A1) and 4) biliary excretion via efflux (MRP2) transporters. 


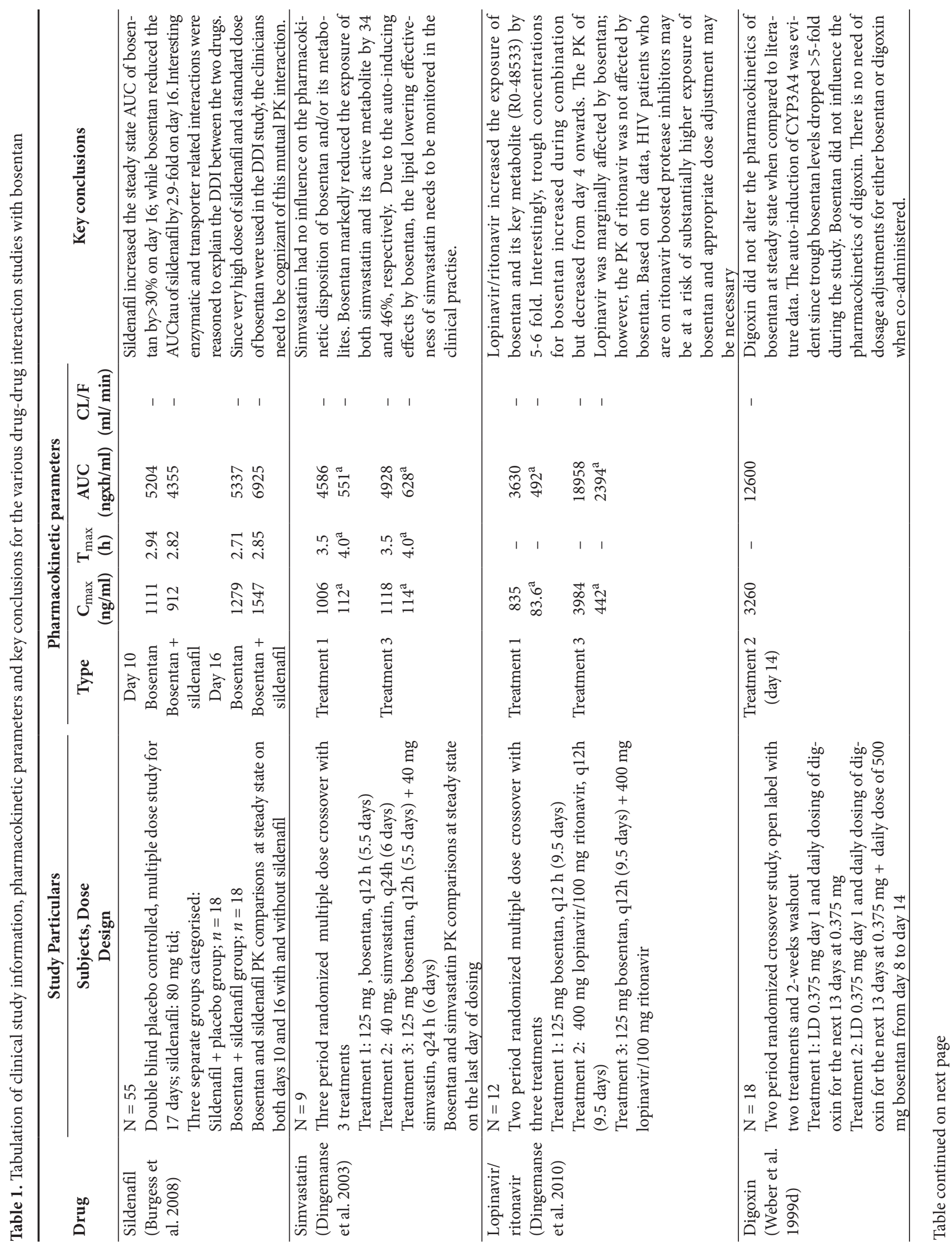




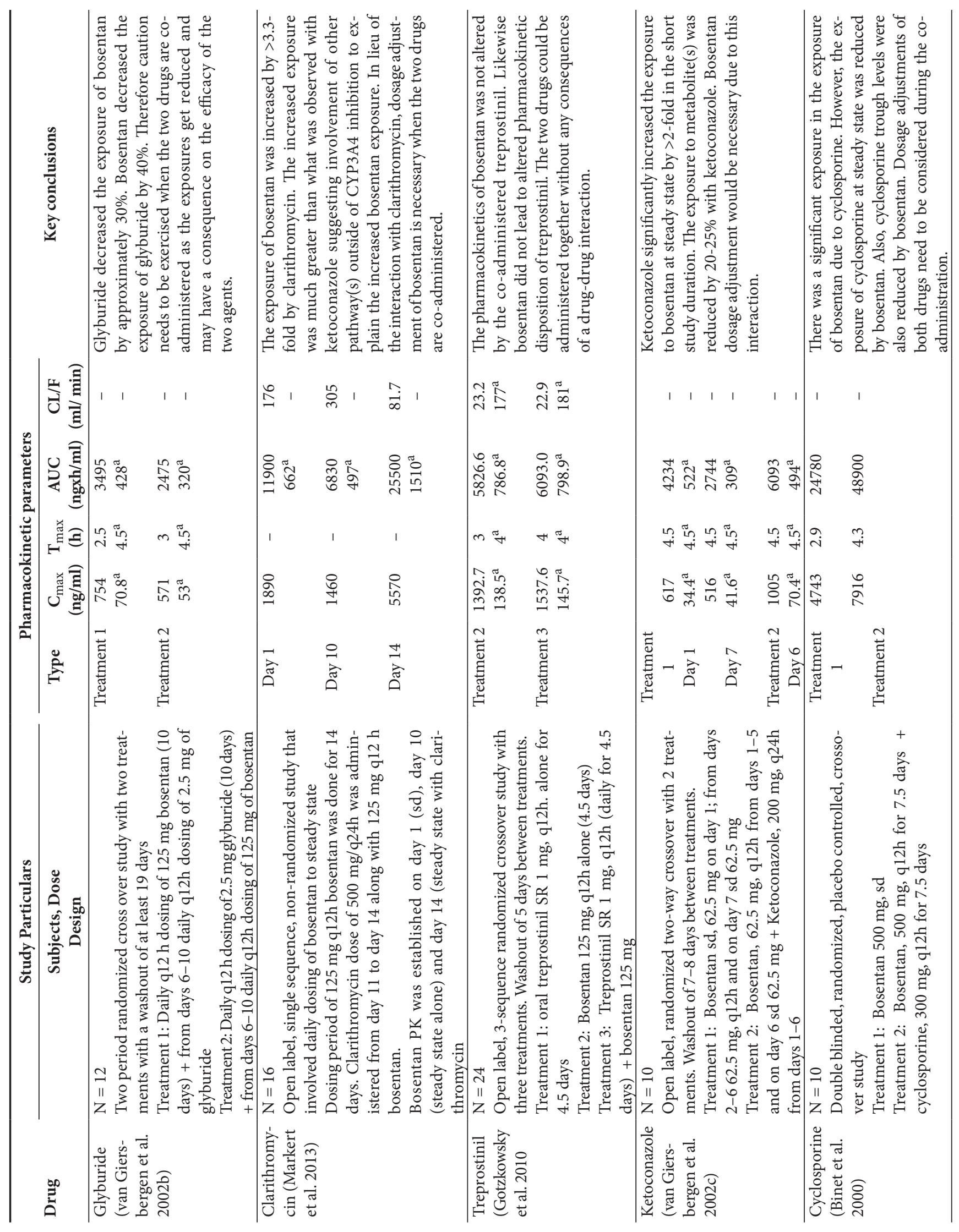


Prior to this ground breaking work of Fahrmayr et al. (2013), characterization of oxidative metabolites formed via CYP3A4 and CYP2C9 enzymes was available (Figure 1) (Weber et al. 1999b; van Giersbergen et al. 2002a; Treiber et al. 2007). Also, the involvement of OATP1B1 transport for bosentan and Ro 48-5033 was also established with a Michaelis constant $\left(\mathrm{K}_{\mathrm{m}}\right)$ value of $44 \mathrm{mM}$ and $60 \mathrm{mM}$, respectively (Treiber et al. 2007).

However, there was hitherto little information regarding the formation of Phase 2 metabolites of bosentan or the efflux of the Phase 2 metabolites or the parent drug into the bile. Since biliary excretion of bosentan and metabolites account for nearly $90 \%$ of the eliminated drug from the body (Weber et al. 1999b). The mechanism leading to the biliary secretion was important to identify. Previously, the work of Fouassier et al. (2002) has confirmed that bosentan alters the cannalicular bile formation by modulating predominantly the multidrug resistance-associated protein 2 (MRP2) transporter protein expression. Hence there was an impetus to fully understand the molecular mechanism to explain the disposition of bosentan from the time of its absorption to the final stage of biliary excretion.

The study involved firstly generation of a stable transfected cell line that carried the higher mRNA expression for each of the desired functionality that was incorporated to assess metabolism and transport function to reflect the intact in vivo system (Fahrmayr et al. 2013). Subsequently immunoblot analysis and quantification of microsomal enzyme activities ensured the functionality and viability of the transfected cell line for its intended application (Fahrmayr et al. 2013). Once the transfected cell line was operational, further optimization with vector transporter assays and midazolam probe testing ensured the technical applicability of the recombinant cell system for characterization of hepatobiliary elimination of bosentan (Fahrmayr et al. 2013). Accordingly, the use of transfected cell line suggested the involvement of uptake transporters as well as the formation of CYP3A4 mediated metabolites of bosentan. Most importantly, it confirmed the formation of bosentan glucuronide via UGT1A1 and efflux of both bosentan and bosentan glucuronide by the MRP2 efflux transporters.

The recent work of Fahrmayar et al. (2013), when put in context with the known disposition of bosentan (Webber et al. 1999b), enabled the detailed description of the metabolic pathways that govern the disposition of bosentan (Figure 2).

\section{Putative mechanism(s) for liver injury via hepatobiliary transport}

Notwithstanding the clinical benefits of bosentan and sitaxsentan in the management of patients with $\mathrm{PAH}$, both 


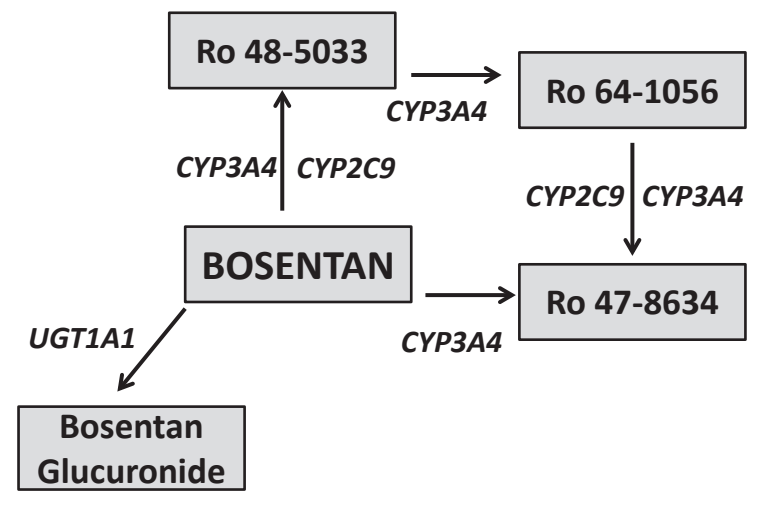

Figure 2. Schematic representation of the various biotransformation involving Phase 1 (CYP3A4 and CYP2C9 enzymes) and Phase 2 (UGT1A1 enzyme) pathways relevant to bosentan.

bosentan and sitaxsetan produce elevated serum transaminase levels leading to liver toxicity (Rubin et al. 2002; Galie et al. 2011). In contrast in a long-term follow-up clinical study involving ambrisentan, the risk of elevation of serum transaminase levels were observed to be less of a concern (Oudiz et al. 2009). Interestingly, although elevations of serum transaminase levels $>3$ times upper limit of normal (ULN) was comparable between macitentan and placebo group, the analysis of data in patients with elevations of transaminase levels $>8$ times upper limit of normal (ULN) suggested that such an occurrence was 5 -fold greater on macitentan as compared to placebo (Channick et al. 2015; TRACLEER ${ }^{\circ}$ product information).

One of the leading hypotheses that may lead to elevated serum transaminase levels and liver toxicity is cantered around perturbations of the hepatobiliary mechanisms involved in the efficient elimination of bile salts (Fattinger et al. 2001; Wang et al. 2003; Kemp et al. 2005; Morgan et al. 2010). These perturbations are due to the net effect which would involve multiple factors such as accumulation of bile salts intracellularly, inhibition of the transporter, altered metabolism and clearance of the bile salts.

The involvement of both uptake and efflux transporters of bile acids/salts are essential to keep a balance: a) uptake: $\mathrm{Na}+$ taurocholate co-transporting polypeptide (NTCP) which is primarily participates in the liver uptake of bile acids and as well as on organic anion-transporting polypeptides which also contributes for the uptake transport of bile acids; $b$ ) efflux: Bile sat export pump (BSEP) which is responsible for the removal of bile components from the liver and multidrug resistance-associated protein 2 (MRP2). Both sitaxsentan and bosentan have been shown to inhibit one or more of uptake or efflux transporters; while sitaxsentan has been documented to inhibit NTCP, organic anion transporter protein (OATP) and BSEP (Hartman et al. 2010), bosentan was shown to inhibit MRP2 and BSEP (Fattinger et al. 2001; Kemp et al. 2005). The importance and key role of BSEP was confirmed in the preclinical transgenic mouse model where BSEP inhibition gradually progressed to severe and fatal cholestasis upon daily cholic acid feeding (Wang et al. 2001a, 2003). Furthermore, Morgan et al. (2010) showed strong correlation between inhibition of BSEP vs. reports of liver toxicity and in a follow-up study which involved a systematic evaluation of hundreds of marketed or withdrawn drugs it was shown that inhibition of BSEP at a certain threshold level was highly correlated with the incidence of liver injury in humans (Morgan et al. 2013). Adding to the evidence of the role of BSEP in causing liver toxicity were few other observations: a) BSEP deficiency due to hereditary defect was shown to cause end-stage liver disease (Strautnieks et al. 1998, 2008; Jansen et al. 1999); b) three case reports of patients with established hereditary BSEP deficiency who underwent liver transplantation re-developed cholestatic dysfunction after transplant and the titre of BSEP antibodies in these patients provided a temporal evidence of the potent inhibition of BSEP transport (Jara et al. 2009); however, immunosuppressive therapy reversed the cholestatic dysfunction in these patients linking the causative role of antibodies (Jara et al. 2009).

Therefore the recent work of Lepist et al. (2014) was focussed on the evaluation of various ERAs such as bosentan, ambrisentan, sitaxsentan and macitentan as potential candidates to influence the hepatobiliary transport and elimination of bile acids and bile salts with the key objectives of understanding possible mechanisms for clinical hepatotoxicity and relative capacities of the candidates to cause cholestatic liver injury.

The work was accomplished using the in vitro sandwich cultured human hepatocytes to ensure similarity and recreate the process to mimic the in vivo situation (Lepist et al. 2014). The work with sandwich cultured human hepatocytes enabled the study of hepatocellular accumulation and efflux of bile acid transport. In order to pin point the mechanisms of possible inhibition of key transporters, in vitro membrane vesicles or transfected cell lines were employed along with the study of model substrates as applicable (Lepist et al. 2014).

As shown in Figure 3a, the employment of sandwich cultured human hepatocytes suggested a concentrationdependent reduction in both total accumulation and cellular accumulation of $\mathrm{d}_{8}$-taurocholate into the hepatocytes. At the top bosentan concentration of $100 \mu \mathrm{M}$, there was approximately $20-30 \%$ reduction in the accumulation of $\mathrm{d}_{8}$-taurocholate. While the biliary efflux of $\mathrm{d} 8$-taurocholate appeared to be minimally effected, the biliary clearance of $\mathrm{d}_{8}$-taurocholate was concentration-dependent (Figures $3 \mathrm{~b}$ and $3 \mathrm{c}$ ). To further understand the molecular mechanisms, the data from the hepatocyte transporter inhibitor assays 


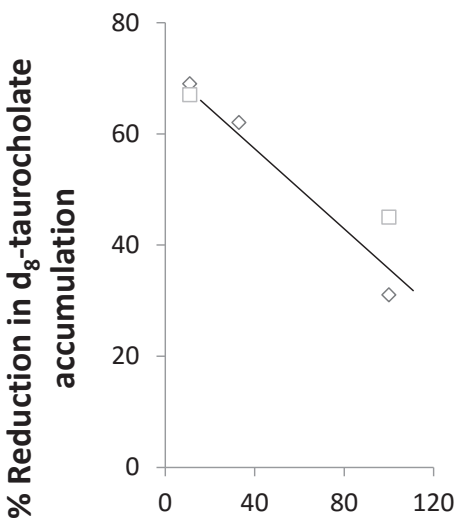

Bosentan concentration $(\mu \mathrm{M})$

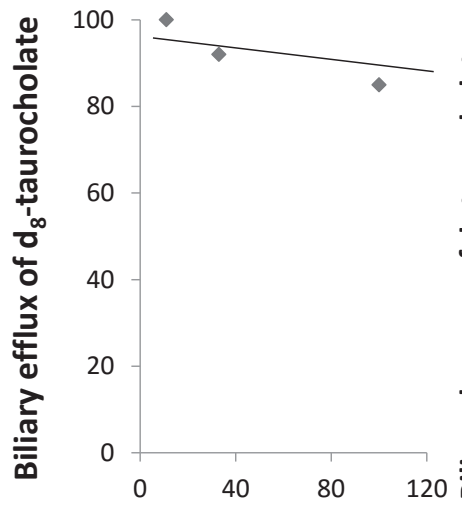

Bosentan concentration $(\mu \mathrm{M})$

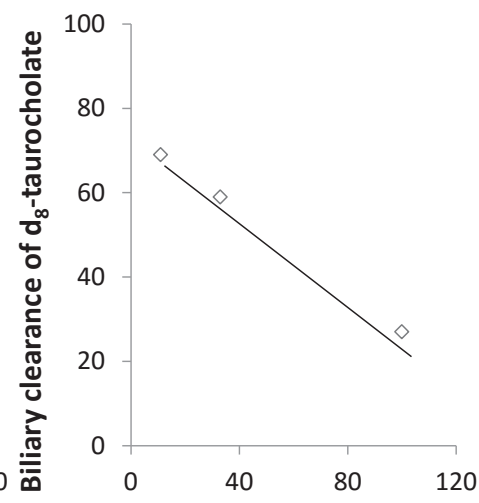

Bosentan concentration $(\mu \mathrm{M})$

Figure 3. Relationship between bosentan concentration and the various intracellular processes comprising of accumulation, efflux and biliary clearance of the target marker $\left(\mathrm{d}_{8}-\right.$ taurocholate).

are presented in Figure 4. The transporters that were maximally affected in the uptake category by bosentan were both OATP1B1 and OATP1B3 with an IC $_{50}$ of $5 \mu \mathrm{M}$ while NTCP inhibition needed a 7-fold higher concentration (Figure 4). With regard to efflux transporters, with the exception of BSEP $\left(\mathrm{IC}_{50}\right.$ value $\left.=42.1 \mu \mathrm{M}\right)$, bosentan did not affect the other three transporters (Figure 4). Interestingly, in this study accumulation of all 4 ERAs was tested in sandwich cultured human hepatocytes (Lepist et al. 2014). The accumulation of bosentan, although relatively higher than ambrisentan, was found to be significantly lower as compared to either macitentan or sitaxsentan; macitentan was found to accumulate the most among all the four ERAs (Lepist et al. 2014). The characterization of hepatic uptake into human hepatocytes with and without rifampicin/cyclosporine suggested a 6-7-fold higher accumulation of macitentan as compared to bosentan and the presence of the transport inhibitors reduced the uptake of either bosentan or macitentan in a proportional manner (Lepist et al. 2014).

\section{Absorption profile dilemma in children relative to adults}

Bosentan is subjected to solubility limited absorption at higher doses; however, the absorption up to $500 \mathrm{mg}$ appeared to obey first order kinetics based on the dose proportional exposure observed in adults. However, at a dose of $1000 \mathrm{mg}$ a clear plateauing of the area under the plasma concentration versus time curve (AUC) was observed suggesting that the saturation limit was exceeded (Weber et al. 1999a). In the study that involved clinical profile delineation and pharmacokinetic characterization of bosentan in children with $\mathrm{PAH}$, it was observed that doses of $2 \mathrm{mg} / \mathrm{kg}$ and $4 \mathrm{mg} / \mathrm{kg}$ produced similar exposure suggesting that solubility limitation in absorption was achieved at a lower threshold in children as compared to adults where the threshold level was at $7 \mathrm{mg} / \mathrm{kg}$ (Beghetti et al. 2009). It was reasoned that discrepancy between adults and children was not due to metabolic or excretory mechanism but was attributable to a physical phenomenon of smaller stomach/intestinal lumen size which may limit the absorptive surface area. Another reason may also be due to specific window of absorption of bosentan in the gut and due to lesser surface area in children vis-à-vis adults it may translate into lower absorption of bosentan. However,

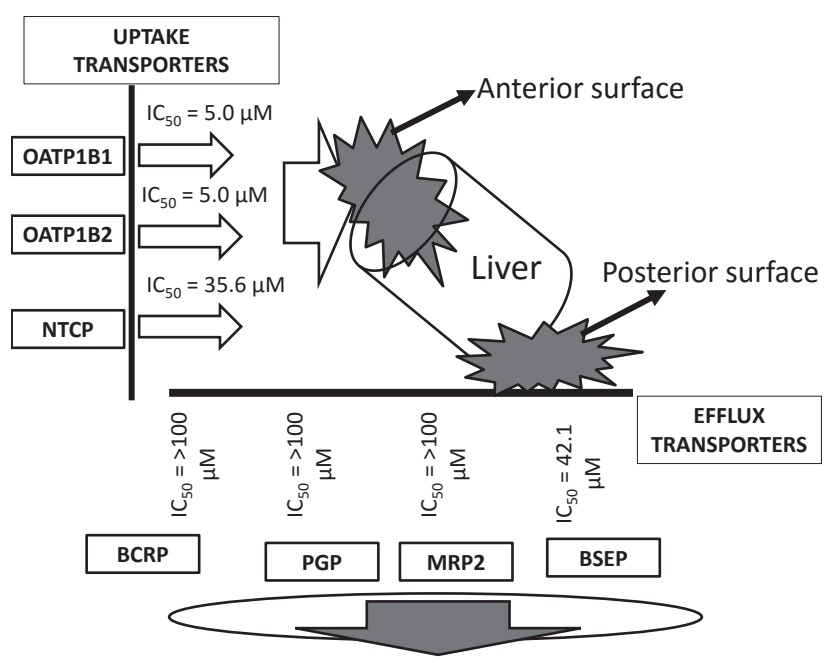

Figure 4. Influence of various uptake transporters (OATP1B1, OATP1B2, NTCP) and efflux transporters (BCRP, PGP, NRP2 and BSEP) that govern the disposition of bosentan. 
the lower absorption profile was not a concern since the clinical activity of bosentan was as good as that observed in adults. In addition, this phenomenon was not just due to a formulation effect since it was observed for the suspension formulation also (Dingemasse et al. 2002).

\section{Drug-drug interaction studies}

\section{Sildenafil}

The multiple dose study carried out by Burgess et al. (2008) showed mutual interaction between the two drugs. Bosentan and sildenafil are both substrates for CYP3A4 (Hyland et al. 2001; Dingemanse et al. 2004) and therefore it should be expected that there is a potential for competitive interaction with CYP3A4. However, since bosentan has the induction capability of CYP3A4 on repeated dosing, the propensity of such an interaction may be greater at steady state. Therefore, as a result of induced CYP3A4, a disproportionate reduction in the AUC of sildenafil was observed at steady state (Burgess et al. 2008). Further support to this observation was provided by an increased metabolite/parent ratio for sildenafil. The pharmacokinetic data obtained on day 10 after daily dosing bosentan, indicated lack of interaction potential of bosentan on the exposure of sildenafil; suggesting the importance of the duration of the study to detect the interaction (Burgess et al. 2008). Hence from a physiological perspective, while the increased duration of daily treatment with bosentan will induce CYP3A4 enzyme, the propensity may differ from individual to individual. Also, it may be important to carry out the interaction study with bosentan for at least 2 weeks. As a consequence of this interaction at therapeutically relevant bosentan doses, the exposure to sildenafil was substantially decreased. However, the formation of the active metabolite of sildenafil may have somewhat compensated for the reduced parent levels from a $\mathrm{PD} /$ efficacy perspective.

Since bosentan is also a substrate for CYP3A4 the auto induction of CYP3A4 expression by bosentan can lead to its own rapid metabolism (Weber et al. 1999a; Dingemanse et al. 2004). Therefore, the steady state data in this study with the placebo reflects the reduced exposure of bosentan due to auto-induction phenomenon (Burgess et al. 2008). Once again glaring difference was observed between the exposure values of bosentan on day $10 v$ s. day 16 (Burgess et al. 2008). However, in the presence of sildenafil, the bosentan exposure increased suggesting that sildenafil directly was competing with bosentan for metabolism with CYP3A4 (Burgess et al. 2008). Also, it is possible that competition may have occurred at the OATP/BCRP transporter level for a possible inhibition of the uptake or efflux transport of bosentan leading to an increased exposure when dosed together (Treiber et al. 2007).
Because both sildenafil and bosentan are approved drugs for the treatment of $\mathrm{PAH}$ and in combination have been shown to be a promising therapeutic option for PAH (Hoeper et al. 2004; Mogollon et al. 2006), it may be very important to carefully review such an interaction to ensure the efficacy and/or safety is not compromised.

\section{Simvastatin}

While simvastatin did not influence the disposition of bosentan, the co-administration of bosentan significantly reduced the exposure of simvastatin (Dingemanse et al. 2003). It was not expected that simvastatin would alter the pharmacokinetics of bosentan since it is not known to be an inhibitor or inducer of CYP3A4 or CYP2C9 (Prueksaritanont et al. 1997). However, there was a potential for a possible interaction via the lactone of simvastatin which has the capacity to inhibit Pgp-related efflux transport (Wang et al. 2001b). But the pharmacokinetics of bosentan was not altered in this study (Dingemanse et al. 2003) suggesting that perhaps bosentan is not a substrate for Pgp efflux. However, it is conceivable that given the reduced exposure of simvastatin it may have not achieved the required threshold in vivo to elicit Pgp inhibition (Wang et al. 2001b).

A number of interesting observations were noted in this drug-drug interaction study (Dingemanse et al. 2003). There was a continuous drop in the $\mathrm{C}_{\text {trough }}$ of bosentan starting from day 2 and until the day of the full pharmacokinetic profiling. The phenomenon occurred with or without the presence of simvastatin, suggesting that even a substrate such as simvastatin was not able to arrest the auto-induced bosentan metabolism by competing with the CYP3A4 enzymes (Dingemanse et al. 2003). Therefore, it was not surprising that bosentan pharmacokinetics was unaltered in the study. On the contrary, the pharmacokinetics of simvastatin and its metabolite were altered (Dingemanse et al. 2003) because of the strong dependence of both simvastatin and metabolite on CYP3A4 enzyme (Prueksaritanont et al. 1997). The lack of any noticeable impact on the $C_{\max }$ of either simvastatin or metabolite by bosentan suggested that hepatic CYP3A4 was being induced rather than intestinal CYP3A4.

The study provided some interesting clues from a mechanistic perspective (Dingemanse et al. 2003) which could be deduced in relation to a previous study (Kyrklund et al. 2000). The other known CYP3A4/CYP2C9 inducer namely rifampicin showed a 2-3-fold higher reduction of simvastatin and its metabolite when co-administered in a multiple dose study (Kyrklund et al. 2000). The larger impact in the reduction suggested that rifampicin may affect the presystemic metabolism of simvastatin and its metabolite as well as the hepatic metabolism; as a result of this interaction even the half-life values of simvastatin and its metabolite were 
altered (Kyrklund et al. 2000). In comparison to rifampicin, bosentan appeared to be a milder auto-inducer (Dingemanse et al. 2003). In a head to head study, the assessments of the in vivo induction capacities of both rifampicin and bosentan was made using R-warfarin as a specific substrate. The exposure of R-warfarin was reduced by 1.6-fold by bosentan in relation to a 3 -fold reduction by rifampicin (Heimark et al. 1987; Weber et al. 1999c). Typically auto-inducing effects are observed for compounds that are either constitutive adrostane receptor (CAR) or pregnane XR receptor (PXR) agonists (Fuhr 2000; Quattrochi and Guzelian 2001).

\section{Lopinavir/ritonavir}

Although lopinavir is a CYP3A4 substrate, the autoinduction caused by bosentan apparently had no bearing on its pharmacokinetics (Dingemanse et al. 2010). Because of elevated bosentan levels it would be expected that it may have an indirect consequence on the exposure of lopinavir but the data was not suggestive of such an occurrence (Dingemanse et al. 2010). However, it was interesting to note that the trough levels of lopinavir continued to fall during the co-administration of bosentan. The same phenomenon was not observed for ritonavir (Dingemanse et al. 2010).

Bosentan trough levels initially went up during the co-administration with lopinavir/ritonavir presumably as a direct result of CYP3A4 inhibition. However after day 4, the trough levels of bosentan declined steadily during the course of the treatment (Dingemanse et al. 2010). While the steady-state trough levels of bosentan declined, the extent of exposure of bosentan increased during the co-ingestion of the drugs (Dingemanse et al. 2010). This strongly suggested that the increased bioavailability of bosentan during the coadministration lopinavir/ritonavir was mediated by the inhibition of the intestinal CYP3A4 by ritonavir. However, since induction of hepatic CYP3A4 was imminent as a result of excess bosentan generated by the ritonavir interaction, it led to the continuous drop of bosentan in spite of its increased bioavailability. The hypothesis that ritonavir inhibited the CYP3A4 metabolism of bosentan is well supported by the well-established role of ritonavir in CYP3A4 inhibition (Greenblatt and Harmatz 2015; Greenblatt 2016). In order to explain the $>5$-fold increase in exposure (Dingemanse et al. 2010), it was postulated that another mechanism may be involved because ketoconazole a very potent CYP3A4 inhibitor only caused a 2 -fold increase in AUC of bosentan (van Geinsberg et al. 2002a).

Both bosentan and R0-48533 are substrates for OATP1B1 (Treiber et al. 2007) and therefore, it is possible that ritonavir, a potent inhibitor of OATP1B1 as demonstrated by the interaction study with statins (Hirano et al. 2006) would have additionally inhibited the hepatic uptake of bosentan and its metabolite leading to a substantially higher exposure of bosentan than would be expected from CYP3A inhibition alone.

\section{Digoxin}

Because digoxin is a substrate for Pgp, the study was rationalized that high daily doses of bosentan may influence the Pgp efflux mechanisms both at the intestinal and renal level (Webber et al. 1999d). The concomitant daily intake of bosentan may alter the pharmacokinetics of digoxin, a drug that needs to be carefully titrated given its narrow therapeutic index.

From a physiological perspective it was not expected that the two drugs would pose a challenge of drug-drug interaction when given together. This is because the metabolic fate of bosentan is controlled by hepatic metabolism and biliary excretion; while that of digoxin is primarily governed by kidneys via renal elimination of the intact drug.

The physiological mechanism for both control/regulation of systemic and renal hemodynamics is mediated via ET-1 (Clavell and Burnett 1994; Noll et al. 1996). Especially in certain pathological conditions inclusive of renal failure, elevated systemic levels of ET-1 have been reported (Clavell and Burnett 1994; Pernow et al. 1998). In a pig model, the renal vasculature was found to respond to the vascoconstricting effect of ET-1 (Pernow et al. 1998). In a similar situation, renal vasculature in man expresses ET-1 receptors and the intravenous infusion of ET-1 in healthy humans caused decreased renal blood flow as a direct consequence of increased renal vascular resistance (Maguire et al. 1994). Hence it was postulated that drugs such as bosentan which is a potent $\mathrm{ET}_{\mathrm{A}}$-specific $\mathrm{ET}$-1 receptor antagonist may provide therapeutic benefit in acute and chronic renal failure by modulating the renal blood flow (Ignasiak et al. 1997).

The consequence of increased renal blood flow may have a bearing on the digoxin elimination since it augments the tubular secretory clearance of digoxin (Koren 1987). Such a drug-drug interaction is not uncommon for digoxin since it has been shown to occur with hydralazine or sodium nitroprusside in congestive heart failure patients on a standard digitalization therapy (Cogan et al. 1981). Another area that contributes for the renal tubular elimination of digoxin is the Pgp mediated efflux mechanism (Dorian et al. 1988) The blockade of Pgp-mediated efflux by cyclosporine led to very high circulatory levels of digoxin (Dorian et al. 1988).

In the short duration of 1-week co-administration of bosentan at a relatively high dose, there was a minimal alteration in the steady-state pharmacokinetics of digoxin; there was a slight reduction in the numerical AUC values for digoxin at steady state (Weber et al. 1999d). Due to high-dose administration of bosentan, it translated into a significant drop in the trough levels of bosentan of $>5$-fold within the first week of administration. However, digoxin 
did not alter the pharmacokinetics of bosentan (Weber et al. 1999d).

\section{Glyburide}

The PK study was originally planned to address the possibility that the increase in liver transaminase levels was related to an increased bosentan interaction when coadministered with glyburide in patients with chronic heart failure on both drugs (van Giersbergen et al. 2002b).

Because bosentan is a moderate inducer of number of CYPs such as CYP3A4, CYP2C9, CYP2C19, the study confirmed that glyburide was a substrate for the various CYPs that bosentan was likely to induce (van Giersbergen et al. 2002b).

While the study did not find a pharmacokinetic reason to explain the increased liver transaminase levels, it proposed an interesting mechanism where both bosentan (with active metabolite, Ro-58533) and glyburide could potentially act synergistically via inhibition of the bile salt export pump (BSEP) (van Giersbergen et al. 2002b). BSEP is necessary for the elimination of bile salts from the hepatocytes (Gerloff et al. 1998). BSEP inhibition has been proposed as a molecular mechanism for the induction of cholestatis (Bolder et al. 1999; Stieger et al. 2000).

Since bosentan and its metabolite can significantly inhibit BSEP (Fattinger et al. 2001) and when coupled with glyburide which can also independently inhibit BSEP (Steiger et al. 2000), the two in combination of the two drugs can cause an imbalance in the bile salt transport leading to accumulation and occurrence of severe cholestasis.

Interestingly, the CYP3A4 induction phenomenon of the two agents mutually was responsible for the reduction in the exposures of both drugs. However, the induction phenomenon has not been documented in an in vivo setting for glyburide. The work of Golstein et al. (1999) suggested that rather than Pgp induction it was the Pgp inhibition of glyburide that was the culprit. The inhibition of Pgp is not relevant because bosentan is not a substrate for Pgp and inhibition of Pgp, if any, as a result of glyburide coadministration should have only contributed for an increase in the bosentan levels.

\section{Clarithromycin}

The increase in the exposure of bosentan was expected in a short study with clarithromycin since clarithromycin is a potent CYP3A4 inhibitor as well as other intestinal and hepatic uptake/efflux transporters (Markert et al. 2013). The magnitude of increase in the exposure of bosentan was unexpected and it was more than what was observed when bosentan was given with ketoconazole. (Markert et al. 2013). Since the study design incorporated measurements of midazolam clearance to monitor CYP3A4 activity, it was observed that bosentan CYP3A4-mediated clearance did not correlate with the CYP3A4-mediated clearance obtained by using the probe (i.e. midazolam) substrate (Markert et al. 2013). Because bosentan showed substantially decreased clearance, it was hypothesized that clarithromycin may additionally inhibit OATP1B1 and OATP1B3 (Seithel et al. 2007); whereas ketoconazole can only inhibit (OATP1B1 (Karlgren et al. 2012). Also, since there was a report that bosentan may also be a substrate to Pgp (Hartman et al. 2010), it was also likely that clarithromycin may have inhibited the Pgp efflux pump. However, CYP2C9 inhibition was ruled out since clarithromycin is not known to inhibit CYP2C9 (Bruce et al. 2001).

Because of the inclusion of midazolam probe in this study, it was possible to tease out the auto-induction related decreased clearance of bosentan. Since the clearance of bosentan far exceeded the CYP3A4-mediated midazolam clearance, it showed that auto-inducing effects may be extended to other enzymes/transporters. One possibility would be CYP2C9 induction which has been confirmed both in vitro (Weiss et al. 2011) and in vivo via CYP2C9 specific substrate S-warfarin (Weber et al. 1999c). Since bosentan is an auto-inducer of pregnane $\mathrm{X}$ receptor bosentan (van Giersbergen et al. 2002) can affect other targets including Pgp (Weiss et al. 2011). However, in vivo this does not appear to translate substantially as evidenced by almost marginal reduction in digoxin exposure on co-administration with bosentan (Weber et al. 1999d).

\section{Treprostinil}

Because treprostinil was metabolized to a small extent by CYP2C9, there was a slight possibility of drug-drug interaction since bosentan can induce CYP2C9. Therefore it was anticipated that there could be a reduction in the exposure of treprostinil. However, the data suggested no interaction between treprostinil and bosentan because the majority portion of treprostinil was subjected to metabolism by CYP2C8 (Gotzkowsky et al. 2010).

In light of a recently published work on treprostinil, there was an evidence of CYP3A activation in the rat liver after multiple dose treatment (Ghonem et al. 2012). However, such translatability has not been hitherto reported in humans. Perhaps a longer duration of dosing of treprostinil along with continuous daily dosing of bosentan may translate into more CYP3A4 induction; however, this hypothesis was not tested since the drug-drug interaction study was a single-dose study with bosentan (Gotzkowsky et al. 2010).

\section{Ketoconazole}

In order to provide context to the drug-drug interaction study of bosentan with ketoconazole (van Giersbergen et 
al. 2002b) the following considerations are provided: a) bosentan has been shown to increase the urinary excretion of 6-beta-hydroxycortisol an endogenous marker of CYP3A4 activity by approximately 1.7-fold (Ged et al. 1989; Ohnhaus et al. 1989); b) bosentan has been unequivocally shown to decrease the exposure of cyclosporine and Rwarfarin (Weber et al. 1999c; Binet et al. 2000) both being CYP3A4 substrates and S-warfarin (Weber et al. 1999c) being a CYP2C9 substrate).

In contrast to what was observed for bosentan with the co-administration of ketoconazole (van Giersbergen et al. 2002c) midazolam whose clearance is solely mediated by CYP3A4 but with a similar bioavailability as bosentan (Garzone et al. 1999) showed significant interaction with keto - resulting which resulted in a 16-fold increased exposure of midazolam (Tsunoda et al. 1999). However, in this study bosentan showed a modest 2-fold increase in its exposure (van Giersbergen et al. 2002b). One possible reason for the subdued increase in the levels of bosentan may be that bosentan underwent metabolism and/or excretion through other pathways independent of the effect(s) of ketoconazole. Also another speculative hypothesis was that since bosentan can auto induce CYP3A4 enzymes on repeated dosing, the increased CYP3A4 levels may negate the complete effect of ketoconazole.

\section{Cyclosporine}

The design of the interaction study of bosentan and cyclosporine was prompted by the hypothesis that there may be therapeutic benefit offered by bosentan to improve the renal hemodynamics in renal transplant patients (Binet et al. 2000). Because cyclosporine caused renal toxicity mediated by vasoconstrictive effects, the presence of bosentan may possibly attenuate the toxicity by modulation of the renal vascular tone in general (Perico et al. 1990; Fogo et al. 1992). Accordingly, significant improvement in the renal perfusion volume was noted in the study in bosentan-treated cohorts and more importantly, bosentan completely arrested the renal hypoperfusion and the typical bi-modal fall of the renal perfusion peak in the cyclosporine cohort (Binet et al. 2000). Because the upward dose titrations of cyclosporine were done throughout the study, the positive effects of renal hemodynamics can be attributed to the bosentan effects but not due to reduced cyclosporine exposure (Binet et al. 2000). Another important point to note was that bosentan was unable to control the cyclosporine-related rise in the systemic blood pressure suggesting that the mechanism(s) for the rise in the blood pressure may be independent of ET receptor modulation (Binet et al. 2000).

Since the exposure of bosentan increased and that of cyclosporine decreased, necessitating upward dose titrations of cyclosporine (Binet et al. 2000), there may be overlap of molecular mechanisms to explain the observed interaction. Since both bosentan and cyclosporine are substrates to CYP3A4, the auto-induction of CYP3A4 by bosentan should have led to the lower exposure of both drugs. While cyclosporine is also a potent inhibitor of CYP3A4, the inhibition of CYP3A4 must have overcome the auto-inducing capacity to elevate bosentan levels. Because it is somewhat farfetched to use this hypothesis, two other alternate mechanisms are proposed: a) the inhibition of CYP3A4 by cyclosporine is more directed towards intestinal CYP3A4; b) the auto-induction of CYP3A4 is primarily at the hepatic level. Hence, differential metabolism of bosentan and cyclosporine may have occurred due to the relative affinities of the two drugs and differences in the CYP3A4 expression between the intestine and liver. Since cyclosporine can also effectively block the liver uptake of bosentan, it may be possible that lower induction of CYP3A4 may have occurred and consequent to both mechanism increased bosentan was observed in the presence of cyclosporine. One other alternate mechanism relates to the competition of Phase 2 metabolism and biliary excretion: it may be possible that cyclosporine may preferentially get conjugated and excreted via bile as compared to bosentan leading to decreased cyclosporine and increased systemic levels of bosentan. Indirect evidence to this hypothesis was supported by an increased bioavailability of cyclosporine when co-administered with tigecycline whose disposition is governed by significant biliary excretory pathway (Srinivas 2009).

\section{Tadalafil}

The well-planned steady-state pharmacokinetic interaction study between tadalafil and bosentan suggested drug-drug interaction potential (Wrishko et al. 2008). However, unlike sildenafil, another member of the same PDE-5 class (Burgess et al. 2008), tadalafil did not influence the exposure of bosentan in this study. The reduced exposure of tadalafil, a substrate for CYP3A4 enzyme, was attributed to the autoinduction of the CYP3A4 enzymes produced by bosentan. Therefore, although the exposures of the two PDE-5 inhibitors are reduced by concomitant bosentan treatment, it was interesting to note that sildenafil but not tadalafil reduced the exposure of bosentan. The above observations need to be factored in making a drug combination strategy of a PDE-5 inhibitor with bosentan in the clinic based on the $\mathrm{PAH}$ patient's requirement.

\section{Rifampicin}

The pharmacokinetic interaction study between rifampicin and bosentan suggested drug-drug interaction potential (van Giersbergen et al. 2007). As expected, a 6-day treatment with rifampicin resulted in a 2 to 2.5 -fold reduction in the 
steady state exposure of bosentan and its metabolite. Since bosentan can cause auto-induction, the data with rifampicin suggested additivity of the two drugs in the activation of the pregnane X nuclear receptor (van Giersbergen et al. 2002d).

\section{Perspectives}

The number of drug-drug interaction studies covered in this review when put in context with the mechanistic aspects unequivocally demonstrates that the use of bosentan needs be done with caution. However, this should not deter the clinical utility of bosentan in $\mathrm{PAH}$ patients if: a) suitable dosage adjustment(s) of either bosentan or the co-administered drug is made; b) appropriate monitoring protocol is in place to verify the clinical use of the drug combination from a safety angle.

On the issue of auto-induction caution needs to be exercised since it may not universally affect all the coadministered drugs. This was evident with lack of effect on the pharmacokinetics of lopinavir, a CYP3A4 substrate, in spite of CYP3A4 induction caused by bosentan. However, it should be noted that the presence of ritonavir, a potent CYP3A4 inhibitor, as part of the lopinavir regimen may have somewhat arrested CYP3A4-related metabolism of lopinavir. As noted in the review, ketoconazole was able to modestly decrease the exposure of bosentan as compared to midazolam suggesting that there may other mechanism(s) in play for bosentan. Therefore, if any new drug is added to bosentan, the auto-inducing effects (victim or perpetrator) need to be considered in a diligent manner.

Since biliary excretion of the intact parent drug and its formed metabolites are critical for the disposition of bosentan, it may be very important to review the clinical pharmacology of the co-administered drugs to understand the degree of involvement of biliary excretory pathways in its elimination. In case biliary excretory mechanisms are involved for the co-administered drugs, it needs to be ascertained if the co-administered drug can be classified as a victim or a perpetrator for arriving at appropriate dosing decisions.

Given the increased consumption of flavonoids as dietary supplements, the PAH patients who are on stable therapy with bosentan need to be cautious of including dietary supplements that have flavonoids (Srinivas 2015a). Because the disposition of several flavonoids such as biochanin A, baicalin, quercetin etc. are controlled by presystemic metabolism with the formation of Phase 2 conjugates and involvement of biliary excretory mechanisms with transporters (Srinivas 2010, 2015a, 2015b), opportunity exists for a drug-drug interaction potential of flavonoids when consumed with concomitant bosentan administration.
Dosing considerations of bosentan and monitoring may be critical for patients that have varying degrees of hepatic impairment, elderly patients who generally exhibit reduced hepatic metabolism, and/or patients who may suffer from not having a fully functional biliary excretory pathway. The administration of bosentan to such patients needs to be done with caution because any impediment to metabolism and biliary excretion mechanisms may increase the exposure of bosentan.

If one suspects a reduced exposure of bosentan (victim) with the co-administered drug such as rifampicin (perpetrator), it may be important to consider the following course of actions in the interest of preserving efficacy in PAH patients: a) switch the perpetrator drug to an alternative agent that may not or minimally exhibit drug-drug interaction with bosentan; b) if increasing the dose of bosentan does not represent an viable option and the switch of the perpetrator drug is not an optimal approach, it may be important to replace bosentan by another ERA.

\section{Conclusions}

Bosentan is an important drug for the treatment of $\mathrm{PAH}$ patients. The disposition of bosentan is largely influenced by the physiological interplay of CYP enzymes and transporters. The other phenomena such as auto-induction, high protein binding and extensive Phase 2 metabolism may need to be considered along with the inspection of the roles of CYP enzymes and transporters in determining the extent of drug-drug interaction potential that bosentan may display with the co-administered drugs. Regardless of bosentan being a victim or perpetrator, the clinical treatment with bosentan need to be carefully weighed in for the dosing decisions in PAH patients who are on other concomitant drugs. Along with the efficacy in PAH patients, the possible role of bosentan on the biliary transporters need to be cautiously viewed for any potential safety issues arising due to liver injury. Despite reports of liver injury, bosentan represents a useful drug in the effective management of PAH. As in any chronic therapy, the continuous assessment(s) of benefit:risk appears to be a good practise in making continuous dosing decisions with bosentan.

\section{References}

Badesch D. B., Champion H. C., Sanchez M. A., Hoeper M. M., Loyd J. E., Manes A., McGoon M. Naeije R., Olschewski H., Oudiz R. J., Torbicki A. (2009): Diagnosis and assessment of pulmonary arterial hypertension. J. Am. Coll. Cardiol. 54 (suppl.), S55-66 http://dx.doi.org/10.1016/j.jacc.2009.04.011

Barst R. J., Gibbs J. S., Ghofrani H. A., Hoeper M. M., McLaughlin V. V., Rubin L. J., Sitbon O., Tapson V. F., Galié N. (2009): Updated 
evidence-based treatment algorithm in pulmonary arterial hypertension. J. Am. Coll. Cardiol. 54 (suppl.), S78-84 http://dx.doi.org/10.1016/j.jacc.2009.04.017

Beghetti M., Haworth S. G., Bonnet D., Barst R. J., Acar P., Fraisse A., Ivy D. D., Jais X., Schulze-Neick I., Galiè N., Morganti A., Dingemanse J., Kusic-Pajic A., Berger R. M. (2009): Pharmacokinetic and clinical profile of a novel formulation of bosentan in children with pulmonary arterial hypertension: the FUTURE-1 study. Br. J. Clin. Pharmacol. 68, 948-955

http://dx.doi.org/10.1111/j.1365-2125.2009.03532.x

Binet I., Wallnofer A., Weber C., Jones R., Thiel G. (2000): Renal hemodynamics and pharmacokinetics of bosentan with and without cyclosporine A. Kidney Int. 57, 224-231 http://dx.doi.org/10.1046/j.1523-1755.2000.00838.x

Bolder U., Trang N. V., Hagey L. R., Schteingart C. D., Ton-Nu H. T., Cerré C., Elferink R. P., Hofmann A. F. (1999): Sulindac is excreted into bile by a canalicular bile salt pump and undergoes a cholehepatic circulation in rats. Gastroenterology 117, 962-971

http://dx.doi.org/10.1016/S0016-5085(99)70356-2

Bruce M. A., Hall S. D., Haehner-Daniels B. D., Gorski J. C. (2001): In vivo effect of clarithromycin on multiple cytochrome P450s. Drug Metab. Dispos. 29, 1023-1028

Burgess G., Hoogkamer H., Collings L., Dingemanse J. (2008): Mutual pharmacokinetic interactions between steady-state bosentan and sildenafil. Eur. J. Clin. Pharmacol. 64, 43-50 http://dx.doi.org/10.1007/s00228-007-0408-z

Channick R. N., Delcroix M., Ghofrani H. A., Hunsche E., Jansa P., Le Brun F. O., Mehta S., Pulido T., Rubin L. J., Sastry B. K., Simonneau G., Sitbon O., Souza R., Torbicki A., Galiè N. (2015): Effect of macitentan on hospitalizations: results from the SERAPHIN trial. JACC Heart Fail. 3, 1-8 http://dx.doi.org/10.1016/j.jchf.2014.07.013

Clavell A. L, Burnett J. C. (1994): Physiologic and pathophysiologic roles of endothelin in the kidney. Curr. Opin. Nephrol. Hypertens. 3, 66-72 http://dx.doi.org/10.1097/00041552-199401000-00010

Cogan J. J., Humphreys M. H., Carlson C. J., Benowitz N. L., Rapaport E. (1981): Acute vasodilator therapy increases renal clearance of digoxin in patients with congestive heart failure. Circulation 64, 973-976 http://dx.doi.org/10.1161/01.CIR.64.5.973

Dingemanse J., Bodin F., Weidekamm E., Kutz K., van Giersbergen P. (2002): Influence of food intake and formulation on the pharmacokinetics and metabolism of bosentan, a dual endothelin receptor antagonist. J. Clin. Pharmacol. 42, 283-289 http://dx.doi.org/10.1177/00912700222011300

Dingemanse J., Schaarschmidt D., van Giersbergen P. L. (2003): Investigation of the mutual pharmacokinetic interactions between bosentan, a dual endothelin receptor antagonist, and simvastatin. Clin. Pharmacokinet. 42, 293-301 http://dx.doi.org/10.2165/00003088-200342030-00004

Dingemanse J., van Giersbergen P. L. (2004): Clinical pharmacology of bosentan, a dual endothelin receptor antagonist. Clin. Pharmacokinet. 43, 1089-11151 http://dx.doi.org/10.2165/00003088-200443150-00003

Dingemanse J., van Giersbergen P. L., Patat A., Nilsson P. N. (2010): Mutual pharmacokinetic interactions between bosentan and lopinavir/ritonavir in healthy participants. Antivir. Ther. 15, 157-163 http://dx.doi.org/10.3851/IMP1506

Dorian P., Strauss M., Cardella C., David T., East S., Ogilvie R. (1988): Digoxin-cyclosporine interaction: severe digitalis toxicity after cyclosporine treatment. Clin. Invest. Med. 11, 108-112

Fahrmayr C., König J., Auge D., Mieth M., Münch K., Segrestaa J., Pfeifer T., Treiber A., Fromm M. (2013): Phase I and II metabolism and MRP2-mediated export of bosentan in a MDCKIIOATP1B1-CYP3A4-UGT1A1-MRP2 quadruple-transfected cell line. Br. J. Pharmacol. 169, 21-33 http://dx.doi.org/10.1111/bph.12126

Fattinger K., Funk C., Pantze M., Weber C., Reichen J., Stieger B, Meier P. J. (2001): The endothelin antagonist bosentan inhibits the canalicular bile salt export pump: a potential mechanism for hepatic adverse reactions. Clin. Pharmacol. Ther. 69, 223-231 http://dx.doi.org/10.1067/mcp.2001.114667

Fogo A., Hellings S. E., Ianagami T., Kon V. (1992): Endothelin receptor antagonism is protective in in vivo acute cyclosporine toxicity. Kidney Int. 42, 770-774 http://dx.doi.org/10.1038/ki.1992.346

Fouassier L., Kinnman N., Lefèvre G., Lasnier E., Rey C., Poupon R., Elferink R. P., Housset C. (2002): Contribution of mrp2 in alterations of canalicular bile formation by the endothelin antagonist bosentan. J. Hepatol. 37, 184-191 http://dx.doi.org/10.1016/S0168-8278(02)00107-1

Fuhr U. (2000): Induction of drug metabolising enzymes: pharmacokinetic and toxicological consequences in humans. Clin. Pharmacokinet. 38, 493-504 http://dx.doi.org/10.2165/00003088-200038060-00003

Galie N., Hoeper M. M., Gibbs J. S., Simonneau G. (2011): Liver toxicity of sitaxsentan in pulmonary arterial hypertension. Eur. Respir. J. 37, 475-476 http://dx.doi.org/10.1183/09031936.00194810

Galie N., Manes A., Branzi A. (2004): The endothelin system in pulmonary arterial hypertension. Cardiovasc. Res. 61, 227-237 http://dx.doi.org/10.1016/j.cardiores.2003.11.026

Garzone P. D., Kroboth P. D. (1999): Pharmacokinetics of the newer benzodiazepines. Clin. Pharmacokinet. 16, 337-364 http://dx.doi.org/10.2165/00003088-198916060-00002

Ged C., Rouillon J. M., Pichard L., Combalbert J., Bressot N., Bories P., Michel H., Beaune P., Maurel P. (1989): The increase in urinary excretion of 6 beta-hydroxycortisol as a marker of human hepatic cytochrome P450IIIA induction. Br. J. Clin. Pharmacol. 28, 373-387 http://dx.doi.org/10.1111/j.1365-2125.1989.tb03516.x

Gerloff T., Stieger B., Hagenbuch B., Madon J., Landmann L., Roth J., Hofmann A. F., Meier P. J. (1998): The sister of P-glycoprotein represents the canalicular bile salt export pump of mammalian liver. J. Biol. Chem. 273, 10046-10050 http://dx.doi.org/10.1074/jbc.273.16.10046

Ghonem N., Yoshida J., Murase N., Strom S. C., Venkataramanan R. (2012): Treprostinil improves hepatic cytochrome P450 activity during rat liver transplantation. J. Clin. Exp. Hepatol. $2,323-332$ http://dx.doi.org/10.1016/j.jceh.2012.09.002 
Golstein P. E., Boom A., van Geffel J., Jacobs P., Masereel B., Beauwens R. (1999): P-glycoprotein inhibition by glibenclamide and related compounds. Pflügers Arch. 437, 652-660 http://dx.doi.org/10.1007/s004240050829

Gotzkowsky S. K, Dingemanse J., Lai A., Mottola D., Laliberte K. (2010): Lack of a pharmacokinetic interaction between oral treprostinil and bosentan in healthy adult volunteers. J. Clin. Pharmacol. 50, 829-834 http://dx.doi.org/10.1177/0091270009351173

Greenblatt D. J. (2016): Evidence-based choice of ritonavir as index CYP3A inhibitor in drug-drug interaction studies. J. Clin. Pharmacol. 56, 152-156 http://dx.doi.org/10.1002/jcph.609

Greenblatt D. J., Harmatz J. S. (2015): Ritonavir is the best alternative to ketoconazole as an index inhibitor of cytochrome P450$3 \mathrm{~A}$ in drug-drug interaction studies. Br. J. Clin. Pharmacol. 80, 342-350 http://dx.doi.org/10.1111/bcp.12668

Hartman J. C., Brouwer K., Mandagere A., Melvin L., Gorczynski R. (2010): Evaluation of the endothelin receptor antagonists ambrisentan, darusentan, bosentan, and sitaxsentan as substrates and inhibitors of hepatobiliary transporters in sandwichcultured human hepatocytes. Can. J. Physiol. Pharmacol. 88, 682-691 http://dx.doi.org/10.1139/Y10-060

Heimark L. D., Gibaldi M., Trager W. F., O'Reilly R. A., Goulart D. A. (1987): The mechanism of the warfarin-rifampin drug interaction in humans. Clin. Pharmacol. Ther. 42, 388-394 http://dx.doi.org/10.1038/clpt.1987.168

Hirano M., Maeda K., Shitara Y., Sugiyama Y. (2006): Drug-drug interaction between pitavastatin and various drugs via OATP1B1. Drug Metab. Dispos. 34, 1229-1236 http://dx.doi.org/10.1124/dmd.106.009290

Hoeper M. M., Dinh-Xuan A. T. (2004): Combination therapy for pulmonary arterial hypertension: Still more questions than answers. Eur. Respir. J. 24, 339-340 http://dx.doi.org/10.1183/09031936.04.00072104

Hyland R., Roe E. G., Jones B. C., Smith D. A. (2001): Identification of the cytochrome $\mathrm{P} 450$ enzymes involved in the N-demethylation of sildenafil. Br. J. Clin. Pharmacol. 51, 239-248 http://dx.doi.org/10.1046/j.1365-2125.2001.00318.x

Ignasiak D. P., McClanahan T. B., Saganek L. J., Potoczak R. E., Hallak H., Gallagher K. P. (1997): Effects of endothelin receptor antagonism with PD 15607 on haemodynamics and renal vascular resistance in rabbits. Eur. J. Pharmacol. 321, 295-300 http://dx.doi.org/10.1016/S0014-2999(96)00954-5

Jansen P. L., Strautnieks S. S., Jacquemin E., Hadchouel M., Sokal E. M., Hooiveld G. J., Koning J. H., De Jager-Krikken A., Kuipers F., Stellaard F. et al. (1999): Hepatocanalicular bile salt export pump deficiency in patients with progressive familial intrahepatic cholestasis. Gastroenterology 117, 1370-1379 http://dx.doi.org/10.1016/S0016-5085(99)70287-8

Jara P., Hierro L., Martinez-Fernandez P., Alvarez-Doforno R., Yanez F., Diaz M. C., Camarena C., De la Vega A., Frauca E., Mu-oz-Bartolo G. et al. (2009): Recurrence of bile salt export pump deficiency after liver transplantation. N. Engl. J. Med. 361, 1359-1367 http://dx.doi.org/10.1056/NEJMoa0901075
Karlgren M., Vildhede A., Norinder U., Wisniewski J. R., Kimoto E., Lai Y., Haglund U., Artursson P. (2012): Classification of inhibitors of hepatic organic anion transporting polypeptides (OATPs): influence of protein expression on drug-drug interactions. J. Med. Chem. 55, 4740-4763 http://dx.doi.org/10.1021/jm300212s

Kemp D. C., Zamek-Gliszczynski M. J., Brouwer K. L. (2005): Xenobiotics inhibit hepatic uptake and biliary excretion of taurocholate in rat hepatocytes. Toxicol. Sci. 83, 207-214 http://dx.doi.org/10.1093/toxsci/kfi020

Koren G. (1987): Clinical pharmacokinetic significance of the renal tubular secretion of digoxin. Clin. Pharmacokinet. 13, 334-343 http://dx.doi.org/10.2165/00003088-198713050-00004

Kyrklund C., Backman J. T., Kivistö K. T., Neuvonen M., Laitila J., Neuvonen P. J. (2000): Rifampin greatly reduces plasma simvastatin and simvastatin acid concentrations. Clin. Pharmacol. Ther. 68, 592-597 http://dx.doi.org/10.1067/mcp.2000.111414

Lepist E. I., Gillies H., Smith W., Hao J., Hubert C., St Claire R. L. 3rd, Brouwer K. R., Ray A. S. (2014): Evaluation of the endothelin receptor antagonists ambrisentan, bosentan, macitentan, and sitaxsentan as hepatobiliary transporter inhibitors and substrates in sandwich-cultured human hepatocytes. PLoS One 9, e87548 http://dx.doi.org/10.1371/journal.pone.0087548

Markert C., Schweizer Y., Hellwig R., Wirsching T., Riedel K. D., Burhenne J., Weiss J., Mikus G., Haefeli W. E. (2013): Clarithromycin substantially increases steady-state bosentan exposure in healthy volunteers. Br. J. Clin. Pharmacol. 77, 141-148 http://dx.doi.org/10.1111/bcp.12177

Maguire J. J., Kuc R. E., O`Reilly G., Davenport A. D. (1994): Vasoconstrictor endothelin receptors characterized in human renal artery and vein in vivo. Br. J. Pharmacol. 113, 49-54 http://dx.doi.org/10.1111/j.1476-5381.1994.tb16172.x

McLaughlin V. V., Archer S. L., Badesch D. B., Barst R. J., Farber H. W., Lindner J. R., Mathier M. A., McGoon M. D., Park M. H., Rosenson R. S. et al. (2009): American College of Cardiology Foundation Task Force on Expert Consensus Documents and the American Heart Association developed in collaboration with the American College of Chest Physicians; American Thoracic Society, Inc.; Pulmonary Hypertension Association. J. Am. Coll. Cardiol. 53, 1573-1619 http://dx.doi.org/10.1016/j.jacc.2009.01.004

Mogollon M. V., Lage E., Cabezon S., Hinojosa R., Ballesteros S., Aranda A., Sobrino J. M., Ordó-ez A. (2006): Combination therapy with sildenafil and bosentan reverts severe pulmonary hypertension and allows heart transplantation: Case report. Transplant. Proc. 38, 2522-2523 http://dx.doi.org/10.1016/j.transproceed.2006.08.074

Morgan R. E., Trauner M., van Staden C. J., Lee P. H., Ramachandran B., Eschenberg M., Afshari C. A., Qualls C. W. Jr, Lightfoot-Dunn R., Hamadeh H. K. (2010): Interference with bile salt export pump function is a susceptibility factor for human liver injury in drug development. Toxicol. Sci. 118, 485-500 http://dx.doi.org/10.1093/toxsci/kfq269 
Morgan R. E., van Staden C. J., Chen Y., Kalyanaraman N., Kalanzi J., Dunn R. T. 2nd, Afshari C. A., Hamadeh H. K. (2013): A multifactorial approach to hepatobiliary transporter assessment enables improved therapeutic compound development. Toxicol. Sci. 136, 216-241 http://dx.doi.org/10.1093/toxsci/kft176

Noll G., Wenzel R. R., Luescher T. F. (1996): Endothelin and endothelin antagonists: Potential role in cardiovascular and renal disease. Mol. Cell. Biochem. 157, 259-267 http://dx.doi.org/10.1007/BF00227908

Ohnhaus E. E., Breckenridge A. M., Park B. K. (1989): Urinary excretion of 6 beta-hydroxycortisol and the time course measurement of enzyme induction in man. Eur. J. Clin. Pharmacol. 36, 39-46 http://dx.doi.org/10.1007/BF00561021

Oudiz R. J., Galie N., Olschewski H., Torres F., Frost A., Ghofrani H. A., Badesch D. B., McGoon M. D., McLaughlin V. V., Roecker E. B., Harrison B. C., Despain D., Dufton C., Rubin L. J., ARIES Study Group (2009): Long-term ambrisentan therapy for the treatment of pulmonary arterial hypertension. J. Am. Coll. Cardiol. 54, 1971-1981 http://dx.doi.org/10.1016/j.jacc.2009.07.033

Patel B. B., Feng Y., Cheng-Lai A. (2015): Pulmonary arterial hypertension: a review in pharmacotherapy. Cardiol. Rev. 23, 33-51

http://dx.doi.org/10.1097/CRD.0000000000000042

Perico N., Dadan J., Remuzzi G. (1990): Endothelin mediates the renal vasoconstriction induced by cyclosporine in the rat. J. Am. Soc. Nephrol. 1, 76-83

Pernow J., Boutier J. F., Franco-Ceredeca A., Lacroix J. S., Matran R., Lundberg J. M. (1988): Potent selective vasoconstrictor effects of endothelin in the pig kidney in vivo. Acta Physiol. Scand. 134, 573-574 http://dx.doi.org/10.1111/j.1365-201X.1988.tb10642.x

Prueksaritanont T., Gorham L. M., Ma B., Liu L., Yu X., Zhao J. J., Slaughter D. E., Arison B. H., Vyas K. P. (1997): In vitro metabolism of simvastatin in humans: identification of metabolizing enzymes and effect of the drug on hepatic P450s. Drug Metab. Dispos. 25, 1191-1199

Quattrochi L. C., Guzelian P. S. (2001): CYP3A regulation: from pharmacology to nuclear receptors. Drug Metab. Dispos. 29, 615-622

Rubin L. J., Badesch D. B., Barst R. J., Galie N., Black C. M., Keogh A., Pulido T., Frost A., Roux S., Leconte I., Landzberg M., Simonneau G. (2002): Bosentan therapy for pulmonary arterial hypertension. N. Engl. J. Med. 346, 896-903 http://dx.doi.org/10.1056/NEJMoa012212

Seithel A., Eberl S., Singer K., Auge D., Heinkele G., Wolf N. B., Dörje F., Fromm M. F., König J. (2007): The influence of macrolide antibiotics on the uptake of organic anions and drugs mediated by OATP1B1 and OATP1B3. Drug. Metab. Dispos. 35, 779-786 http://dx.doi.org/10.1124/dmd.106.014407

Srinivas N. R. (2009): Tigecycline and cyclosporine interaction-an interesting case of biliary-excreted drug enhancing the oral bioavailability of cyclosporine. Eur. J. Clin. Pharmacol. 65, 543-544

http://dx.doi.org/10.1007/s00228-009-0631-x
Srinivas N. R. (2010): Baicalin, an emerging multi-therapeutic agent: Pharmacodynamics, pharmacokinetics, and considerations from drug development perspectives. Xenobiotica 40, 357-367 http://dx.doi.org/10.3109/00498251003663724

Srinivas N. R. (2015a): Biochanin a: understanding the complexities in the paradoxical drug-drug interaction potential. Eur. J. Drug Metab. Pharmacokinet. 40, 119-125 http://dx.doi.org/10.1007/s13318-015-0279-0

Srinivas N. R. (2015b): Recent trends in the preclinical drug-drug interaction studies of flavonoids - review of case studies, issues and perspectives. Phytother. Res. 29, 1679-1691 http://dx.doi.org/10.1002/ptr.5447

Stieger B., Fattinger K., Madon J., Kullak-Ublick G. A., Meier P. J. (2000): Drug- and estrogen-induced cholestasis through inhibition of the hepatocellular bile salt export pump (Bsep) of rat liver. Gastroenterology 118, 422-430 http://dx.doi.org/10.1016/S0016-5085(00)70224-1

Strautnieks S. S., Bull L. N., Knisely A. S., Kocoshis S. A., Dahl N., Arnell H., Sokal E., Dahan K., Childs S., Ling V. et al. (1998): A gene encoding a liver-specific ABC transporter is mutated in progressive familial intrahepatic cholestasis. Nat. Genet. 20, 233-238 http://dx.doi.org/10.1038/3034

Strautnieks S. S, Byrne J. A., Pawlikowska L., Cebecauerova D., Rayner A., Dutton L., Meier Y., Antoniou A., Stieger B., Arnell H. et al. (2008): Severe bile salt export pump deficiency: 82 different $\mathrm{ABCB} 11$ mutations in 109 families. Gastroenterology 134, 1203-1214 http://dx.doi.org/10.1053/j.gastro.2008.01.038

TRACLEER ${ }^{\circledR}$ (bosentan) Actelion Pharmaceuticals US, Inc. Drug Prescribing information (revised Oct 2012). http://www1. actelion.us/documents/us/product-documentation/tracleer(bosentan)-prescribing-information.pdf

Treiber A., Schneiter R., Hausler S., Stieger B. (2007): Bosentan is a substrate of human oatp1b1 and oatp1b3: Inhibition of hepatic uptake as the common mechanism of its interactions with cyclosporin a, rifampicin, and sildenafil. Drug Metab. Dispos. 35, 1400-1407 http://dx.doi.org/10.1124/dmd.106.013615

Tsunoda S. M., Velez R. L., Von Moltke L. L., Greenblatt D. J. (1999): Differentiation of intestinal and hepatic cytochrome P450 3A activity with use of midazolam as an in vivo probe: Effect of ketoconazole. Clin. Pharmacol. Ther. 66, 461-471 http://dx.doi.org/10.1016/S0009-9236(99)70009-3

Tuder R. M., Abman S. H., Braun T., Capron F., Stevens T., Thistlethwaite P. A., Hawort S. G. (2009): Development and pathology of pulmonary hypertension. J. Am. Coll. Cardiol. 54 (suppl.), S3-9

http://dx.doi.org/10.1016/j.jacc.2009.04.009

van Giersbergen P. L., Gnerre C., Treiber A., Dingemanse J., Meyer U. A. (2002a): Bosentan, a dual endothelin receptor antagonist, activates the pregnane X nuclear receptor. Eur. J. Pharmacol. 450, 115-121 http://dx.doi.org/10.1016/S0014-2999(02)02075-7

van Giersbergen P. L., Treiber A., Clozel M., Bodin F., Dingemanse J. (2002b): In vivo and in vitro studies exploring the pharmacokinetic interaction between bosentan, a dual endothelin 
receptor antagonist, and glyburide. Clin. Pharmacol. Ther. $71,253-262$ http://dx.doi.org/10.1067/mcp.2002.122473

van Giersbergen P. L., Halabi A., Dingemanse J. (2002c): Single- and multiple-dose pharmacokinetics of bosentan and its interaction with ketoconazole. Br. J. Clin. Pharmacol. 53, 589-595 http://dx.doi.org/10.1046/j.1365-2125.2002.01608.x

van Giersbergen, P. L., Gnerre, C., Treiber, A., Dingemanse, J., Meyer, U.A. (2002d). Bosentan, a dual endothelin receptor antagonist, activates the pregnane $\mathrm{X}$ nuclear receptor. Eur. J. Pharmacol. 450, 115-121 http://dx.doi.org/10.1016/S0014-2999(02)02075-7

van Giersbergen P. L., Treiber A., Schneiter R., Dietrich H., Dingemanse J. (2007): Inhibitory and inductive effects of rifampin on the pharmacokinetics of bosentan in healthy subjects. Clin. Pharmacol. Ther. 81, 414-419 http://dx.doi.org/10.1038/sj.clpt.6100075

Verhaar M. C., Strachan F. E., Newby D. E., Cruden N. L., Koomans H. A., Rabelink T. J., Webb D. J. (1998): Endothelin-A receptor antagonist-mediated vasodilatation is attenuated by inhibition of nitric oxide synthesis and by endothelin-B receptor blockade. Circulation 97, 752-756 http://dx.doi.org/10.1161/01.CIR.97.8.752

Wang R., Salem M., Yousef I. M., Tuchweber B., Lam P., Childs S. J., Helgason C. D., Ackerley C., Phillips M. J., Ling V. (2001a):Targeted inactivation of sister of P-glycoprotein gene (spgp) in mice results in nonprogressive but persistent intrahepatic cholestasis. Proc. Natl. Acad. Sci. USA 98, 2011-2016 http://dx.doi.org/10.1073/pnas.98.4.2011

Wang E., Casciano C. N., Clement R. P., Johnson W. W. (2001b): HMG-CoA reductase inhibitors (statins) characterized as direct inhibitors of Pglycoprotein. Pharm. Res. 18, 800-806 http://dx.doi.org/10.1023/A:1011036428972

Wang R., Lam P., Liu L., Forrest D., Yousef I. M., Mignault D., Phillips M. J., Ling V. (2003): Severe cholestasis induced by cholic acid feeding in knockout mice of sister of P-glycoprotein. Hepatology 38, 1489-1499 http://dx.doi.org/10.1053/jhep.2003.09037

Weber C., Schmitt R., Birnboeck H., Hopfgartner G., Eggers H., Meyer J., van Marle S., Viischer H. W., Jonkman J. H. (1999a): Multiple-dose pharmacokinetics, safety, and tolerability of bosentan, an endothelin receptor antagonist, in healthy male volunteers. J. Clin. Pharmacol. 39, 703-714 http://dx.doi.org/10.1177/00912709922008344

Weber C., Gasser R., Hopfgartner G. (1999b): Absorption, excretion, and metabolism of the endothelin receptor antagonist bosentan in healthy male subjects. Drug Metab. Dispos. 7, $810-815$

Weber C., Banken L., Birnboeck H., Schulz R. (1999c): Effect of the endothelin-receptor antagonist bosentan on the pharmacokinetics and pharmacodynamics of warfarin. J. Clin. Pharmacol. 39, $847-854$ http://dx.doi.org/10.1177/00912709922008380

Weber C., Banken L., Birnboeck H., Nave S., Schulz R. (1999d): The effect of bosentan on the pharmacokinetics of digoxin in healthy male subjects. Br. J. Clin. Pharmacol. 47, 701-706 http://dx.doi.org/10.1046/j.1365-2125.1999.00946.x

Weiss J., Herzog M., Haefeli W. E. (2011): Differential modulation of the expression of important drug metabolising enzymes and transporters by endothelin-1 receptor antagonists ambrisentan and bosentan in vitro. Eur. J. Pharmacol. 660, 298-304 http://dx.doi.org/10.1016/j.ejphar.2011.04.003

Wrishko R. E., Dingemanse J., Yu A., Darstein C., Phillips D. L., Mitchell M. I. (2008): Pharmacokinetic interaction between tadalafil and bosentan in healthy male subjects. J. Clin. Pharmacol. 48, 610-618 http://dx.doi.org/10.1177/0091270008315315

Wu Y., O‘Callaghan D. S., Humbert M. (2013): An update on medical therapy for pulmonary arterial hypertension. Curr. Hypertens. Rep. 15, 614-622 http://dx.doi.org/10.1007/s11906-013-0394-8

Received: October 27, 2015

Final version accepted: November 22, 2015

First published online: April 5, 2016 